\title{
Development of an Introduction to Circuits Course and Lab for Mechanical Engineering Students via Systematic Design of Instruction
}

\section{Dr. Grant Crawford, Quinnipiac University}

Grant Crawford, PhD, P.E., Colonel (retired) U.S. Army, is a Professor of Mechanical Engineering and the Director of Career Development for the School of Engineering at Quinnipiac University. He is the former Director of the Mechanical Engineering Program at the United States Military Academy at West Point, New York. Grant graduated from West Point in 1985 with a Bachelor of Science degree in Mechanical Engineering. He earned a M.S. degree in Aerospace Engineering from the Georgia Institute of Technology in 1994 and a Ph.D. in Aerospace Engineering from the University of Kansas in 2004. He has taught courses in aeronautics, thermal-fluid systems, heat transfer, computer-aided design, circuits, and aerospace and mechanical engineering design. He is a licensed Professional Engineer and is a rated pilot in both rotary and fixed wing aircraft.

\section{Dr. Jose Antonio Riofrio, Quinnipiac University}

José A Riofrío received his B.S. in Engineering Physics from Elizabethtown College in 2003, and his M.S. and Ph.D. in Mechanical Engineering from Vanderbilt University in 2005 and 2008, respectively. At Vanderbilt, José focused his research in controls, mechatronics and mechanical design. After obtaining his Ph.D., José worked in the Fluid Power industry designing servo-pneumatic control systems for various motion-control applications, such as packaging, automation, and animatronics. In the fall of 2011, became an assistant professor of Mechanical Engineering at Western New England University, where he taught various courses in solid mechanics, mechatronics, and first-year engineering. In the fall of 2015, José joined the faculty at Quinnipiac University (Hamden, CT) as an Assistant Teaching Professor of Mechanical Engineering, where he teaches courses in Circuits, Controls, Solid Mechanics, and Data Acquisition.

\section{Col. Richard Melnyk, U.S. Military Academy}

COL Rich Melnyk is an Army Aviator and the Mechanical Engineering Program Director in the Department of Civil and Mechanical Engineering at the United States Military Academy, West Point. He has a $\mathrm{PhD}$ in Aerospace Engineering, a PE in Mechanical Engineering, an MBA in Technology Management and recently commanded an Army Battalion at Hunter Army Airfield, Savannah, Georgia. 


\title{
"Development of an Introduction to Circuits Course and Lab for Mechanical Engineering Students via Systematic Design of Instruction"
}

\begin{abstract}
In the traditional Mechanical Engineering undergraduate curriculum, students are typically required to take a single introductory Circuits course. Such a course is often designed and taught by Electrical Engineering (EE) faculty and taken by students from various Engineering disciplines, including EE.
\end{abstract}

At Quinnipiac University (QU), there is no EE program and only Mechanical Engineering students are required to take an introductory circuits course. This presented an opportunity to carefully design a course tailored to the specific needs of our students in the context of our curriculum, the post-graduation expectations of our constituents, and current trends in electromechanical system integration. Furthermore, with Mechanical Engineering being a new program at QU, there was also a rare opportunity to design a circuits laboratory space from scratch (infrastructure and equipment).

The focus of this work is the application of the Systematic Design of Instruction (SDI) towards the design of an Introduction to Circuits course targeted to undergraduate Mechanical Engineering students. The goal of this work is to determine if such a course is more effective at achieving student learning outcomes than a course taught to a variety of engineering majors. The SDI, developed by Walter Dick and Lou Carey, is a comprehensive process which begins with the identification of main instructional goals and carefully formulates an instructional strategy based on students' entry and subordinate skills, performance objectives, assessment instruments, and a cyclical formative evaluation of the course for continuous improvement.

As a result of SDI application, the Introduction to Circuits course at QU provides students with foundational knowledge in DC and AC circuits, as well as some building-block knowledge for future courses in Mechatronics, Controls, and Data Acquisition (motors, generators, diodes, strain gages, voltage regulators, and op amps). Finally, through a design project, students apply the knowledge and skills learned in the course and lab to design, simulate, prototype, build, and test a multi-output DC power supply. The final circuits are embodied with Printed Circuit Boards (PCBs) which the students design.

The success of this course is assessed by comparing our students' perception of their circuitsrelated abilities to those of students from a nationally-regarded peer institution (who took circuits as a service course from their EE department) via anonymous surveys administered to both groups (in both cases, 6 to 12 months after completion of the course). In addition, through an internal end-of-semester assessment tool, we compare our students' perception of their ability to achieve each course objective to embedded indicators based on performance in selected course assessments. Finally, evidence of proficiency in circuit design and implementation is manifested in students' subsequent senior capstone projects, in which some groups have designed and built PCBs to power and embody the main electronic components in their designed systems. 


\section{Introduction}

In the fall of 2012, QU held its first freshman engineering class. Mechanical engineering was one of the four inaugural engineering disciplines approved by the university. Starting a new engineering school came with a lot of challenges, but also presented many opportunities. Many of the opportunities came in setting up the initial curriculum, a process that began well in advance of admitting the first class of students. In setting the initial curriculum, the focus was on identifying broad content with specific course content details left for later development. One of the early decisions that was made for the mechanical engineering program was to mandate an introductory circuits course with lab content for the students. Development of the course was left for the second year of the program, after additional faculty had been hired.

Without an electrical engineering program at QU, development of the introductory circuits course offered an opportunity for the mechanical engineering program faculty. In the experience of the faculty, most mechanical engineering program circuits courses are taught as a service course by the institution's electrical engineering program. A review of the undergraduate curricula for 40 mechanical engineering programs was conducted and confirmed this perception. The programs were selected from the 2017 US News and World Report Rankings of top engineering programs. The top 20 engineering programs were selected from the list of institutions without a doctorate and the list of institutions with a doctorate. The list of these programs is in Table 1 [1], [2].

Table 1. List of Institutions Surveyed

\begin{tabular}{|c|c|}
\hline Institutions with Doctorate in Engineering & Institutions with no Doctorate in Engineering \\
\hline Massachusetts Institute of Technology & Harvey Mudd College \\
\hline Stanford University & Rose-Hulman Institute of Technology \\
\hline University of California - Berkeley & Franklin W. Olin College of Engineering \\
\hline California Institute of Technology & United States Military Academy \\
\hline Georgia Institute of Technology & United States Air Force Academy \\
\hline University of Illinois -- Urbana-Champaign & United States Naval Academy \\
\hline University of Michigan -- Ann Arbor & Bucknell University \\
\hline Carnegie Mellon University & Claifornia Polytechnic State University -- San Luis Obispo \\
\hline Purdue University -- West Lafayette & Cooper Union \\
\hline Cornell University & Milwaukee School of Engineering \\
\hline Princeton University & United States Coast Guard Academy \\
\hline University of Texas -- Austin & Lafayette College \\
\hline Northwestern University & University of San Diego \\
\hline Johns Hopkins University & California Polytechnic State University -- Pamona \\
\hline Texas A\&M University -- College Station & Embry-Riddle Aeronautical University -- Prescott \\
\hline University of Wisconsin -- Madison & Kettering University \\
\hline Virginia Tech & Smith College \\
\hline Columbia University & Valparaiso University \\
\hline University of California -- Los Angeles & The Citadel \\
\hline Duke University & Gonzaga University \\
\hline
\end{tabular}

The results of this review indicated that nine of the 40 programs did not require a circuits course. Of the 31 programs that did mandate a circuits course, only four programs taught the course internally to the program as shown in Figure 1. For the 20 programs without a doctorate, $80 \%$ offered their circuits course as a service course as shown in Figure 2 [3]-[42]. 


\section{Undergraduate ME Program Circuits Course Proponents Combined $(\mathrm{N}=40)$}

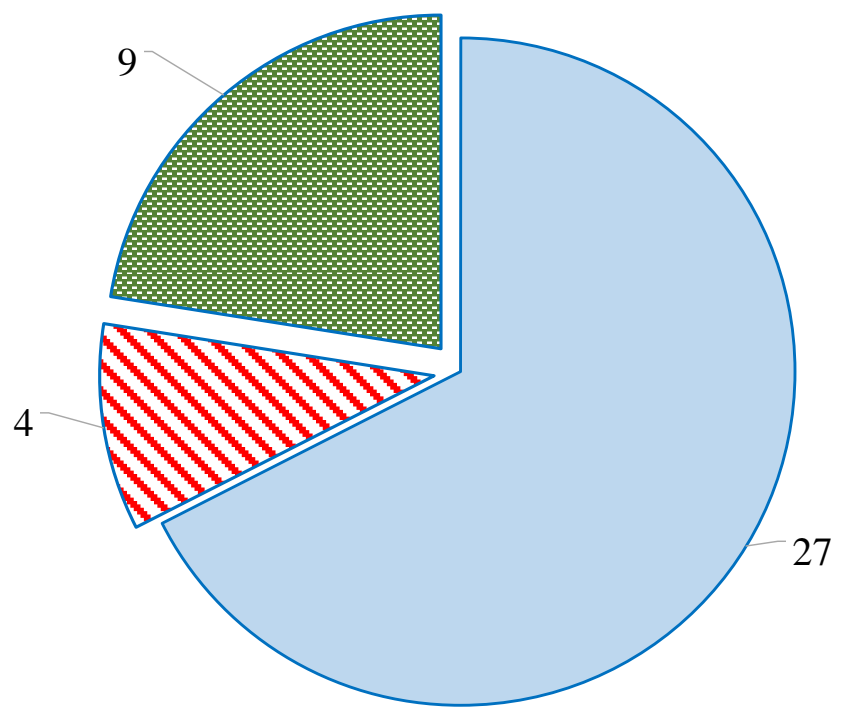

$\square$ Service Course $\quad \square$ In-Department $\quad \square$ Not Required

Figure 1. Circuit Course Proponents for All Surveyed Institutions (N=40) [3]-[42]

\section{Undergraduate ME Program Circuits Course Proponents \\ Institutions without a Doctoral Program $(\mathrm{N}=20)$}

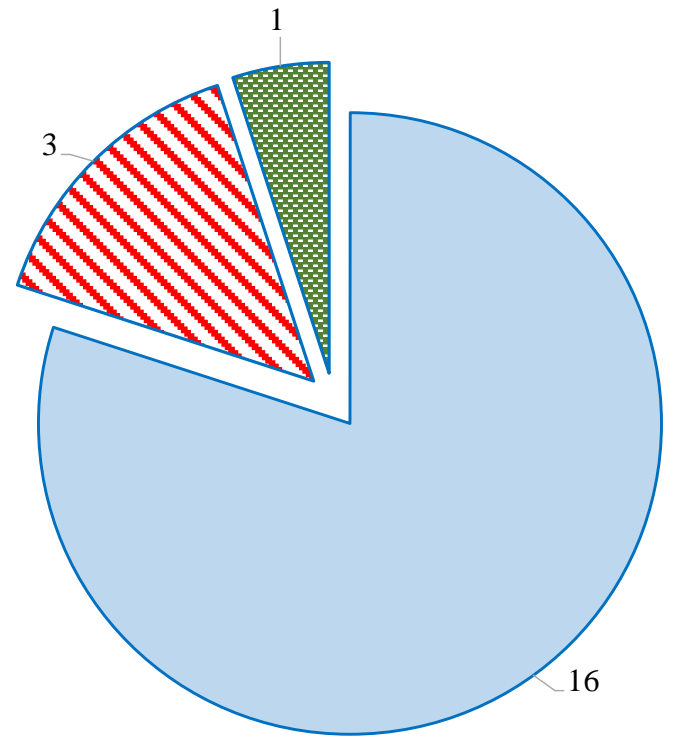

$\square$ Service Course $\quad \square$ In-Department $\quad \square$ Not Required

Figure 2. Circuit Course Proponents for Surveyed Institutions that do not Offer a Doctorate in Engineering $(\mathrm{N}=20)$ [3]-[22] 
The faculty member charged with developing the course had ample sources of sample course syllabi from which to choose for the new course. He was also very familiar with the Systematic Design of Instruction (SDI) as presented in [43]. In the process of reviewing the syllabi from other programs, he asked the question, "Can we do a better job of achieving our objectives for this course by using SDI to methodically design the course and its lab content?” After discussion with the program faculty, the decision was made to design the circuits course and lab content 'from the ground up' using the SDI process.

This paper describes how the SDI process was implemented to design and revise the introductory circuits course. The resulting course syllabus is presented with a description of the major content areas. Results of instructor evaluation of the course objectives using embedded indicators are presented and compared to student survey perceptions of their capabilities. Finally, post-course survey data from students are compared with survey data from students at a similar institution, which uses a service course for its ME majors. Conclusions with regard to the effectiveness of the SDI-designed course are presented.

\section{Methodology - Systematic Design of Instruction}

As previously stated, this course was developed through application of the SDI process [43]. A flowchart of the SDI process is shown in Figure 3. Solid lines represent forward sequential steps, while dashed lines represent feedback resulting from formative evaluation of the instruction and thus highlight the intended iterative nature of SDI.

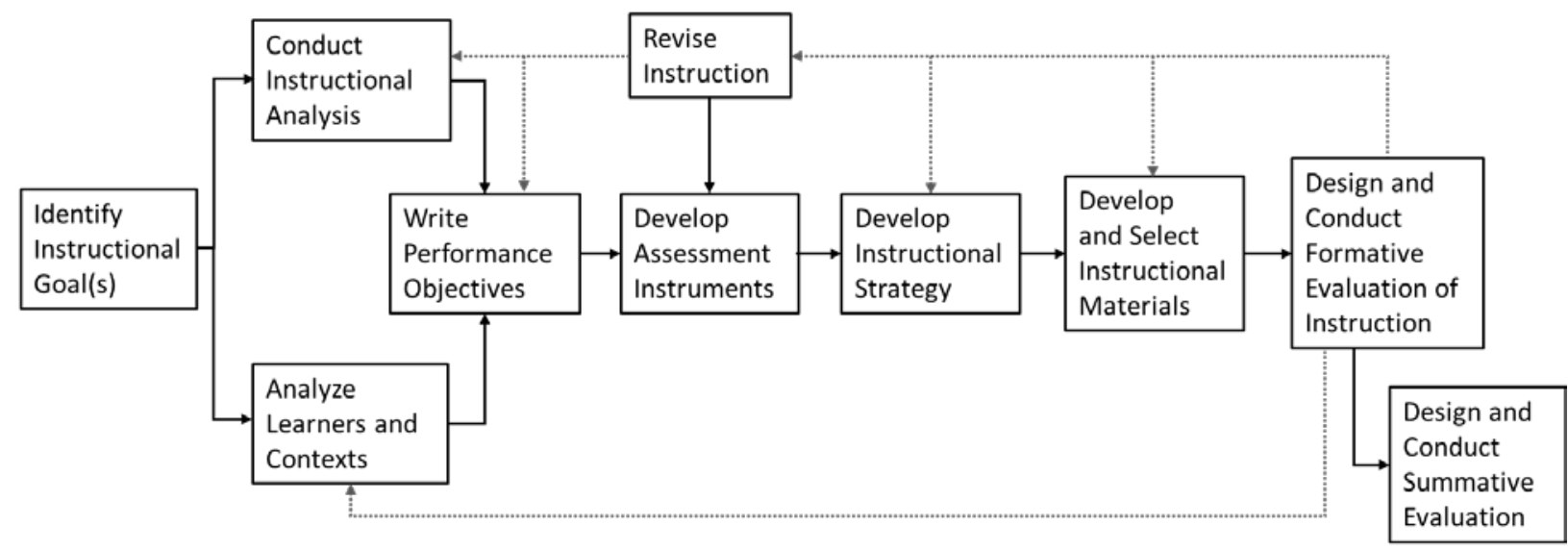

Figure 3: SDI Flowchart [43]

In this section, each step outlined in Figure 3 will be described and its application discussed in the context of the development of our Introduction to Circuits course.

\section{a. Identify Instructional Goals}

The SDI process begins with clear, overarching instructional goals. These are general statements that should indicate the main purpose of this course (i.e., in the context of the curriculum and/or preparing students for specific future endeavors). As specified by Dick, et al [43], these should be expressed as 'statements of behaviors that learners are to demonstrate as a result of instruction'. Instructional goals can be influenced by various sources, such as institutional curricula, internal program assessment, industry needs, professional organizations, emerging 
technologies, etc. It should be noted that these are different than course objectives, which deal with specific knowledge content and skills, and are laid out later in the process.

For this course, we identified three main Instructional Goals:

1. Students shall be adequately prepared for higher-level courses in our curriculum requiring proficiency with electronic circuits. Such subsequent courses are Controls (mandatory), Measurement and Data Acquisition (elective) and Mechatronics (elective).

2. Students shall be well-prepared to take and pass the Electrical Engineering portion of the Fundamentals of Engineering (FE) Examination.

3. Students shall confidently apply circuits-related knowledge and skills when working on their Senior Design Projects.

b. Conduct Instructional Analysis

The main purpose of instructional analysis is to break down the instructional goals into general skills and knowledge that would be required in order to achieve such goals. According to the SDI, this process requires three main steps.

The first step is to categorize each goal into Gagné's Domains of Learning: verbal information, intellectual skills, psychomotor skills, and attitudes. For an engineering course such as Introduction to Circuits, most goals would correlate strongly with intellectual skills. However, hands-on activities such as soldering would be associated with psychomotor skills, and basic knowledge-based definitions (i.e., explaining the definition of current) would fall under "verbal information”.

The second, and by far the most involved step, is to identify the steps, or skills, required in order to attain each individual goal. The SDI proposes a very specific procedure for laying out these steps/skills for a goal depending on which Gagné's Domain it falls under. Each defined skill/step should be further broken down into subordinate skills until arriving at the lowest-level learning required. The outcome of this instructional analysis should be a comprehensive map of the course content domain. As an example, Figure 4 shows the proposed course content of our Introduction to Circuits course resulting from instructional analysis.

The final step in the instructional analysis is to identify all relevant entry skills. This can be done by carefully analyzing each subordinate skill in order to determine what it is that the learners must already know or be able to do before they begin instruction. As an example, Table 2 shows all relevant entry-level skills needed for our Introduction to Circuits course, along with the source of each skill.

\section{c. Analyze learners and contexts}

Since the SDI is intended as a comprehensive methodology for any type of instruction, it stresses the importance of recognizing the general characteristics of the learners, such as demographics, background knowledge, learning styles, etc., as well as contextual information about the instructional setting. Since Introduction to Circuits is to be taught as an undergraduate course in the Mechanical Engineering department at QU, we can do most of this analysis based on the general characteristics and parameters of our program. 


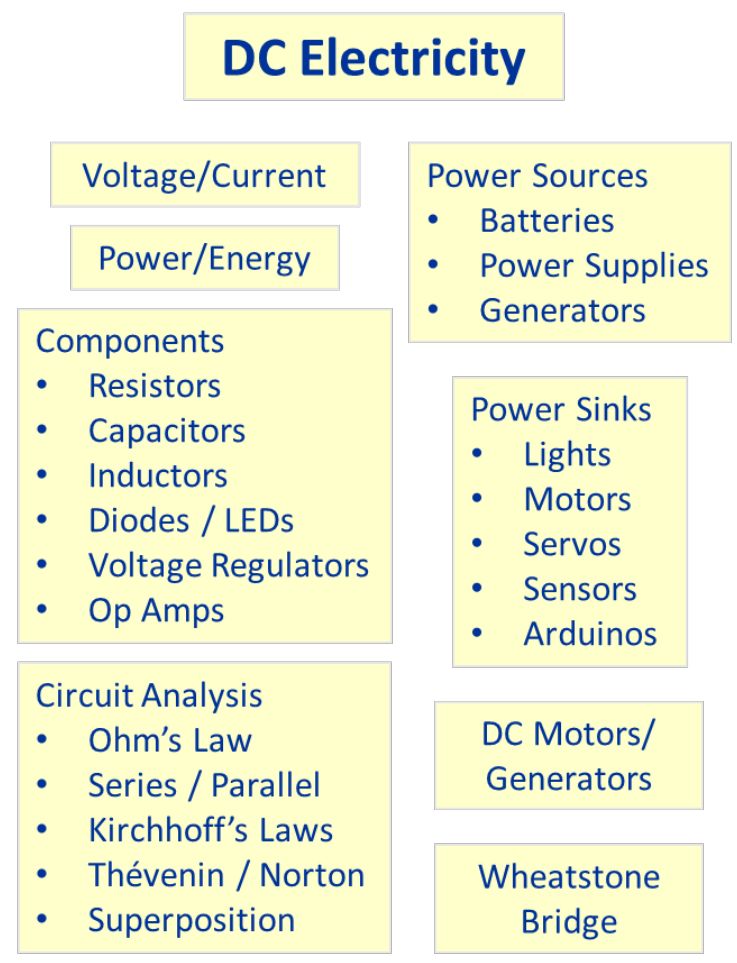

\section{Circuit Design}

Components

- Voltage Regulators

- Switches

- Terminal blocks

Design of a DC

Power Circuit

Circuit Simulation

Circuit prototyping

and breadboarding

PCB design:

- Circuit Layout

- Ordering process

- Populate and test

\section{AC Electricity}

Voltage/Current

Phasors

Power/ Energy

Faraday's Law

Transformers

AC Motors \&

3-phase AC

Basic Circuit

Analysis

Figure 4: Instructional Analysis for Introduction to Circuits Course

Table 2: Entry-level Characteristics

\begin{tabular}{|c|c|}
\hline Knowledge / Skills & Source \\
\hline Verbal / Written Skills & English (EN101, EN102) \\
\hline $\begin{array}{c}\text { Basic Electrical Principles, } \\
\text { Simple Harmonic Motion }\end{array}$ & Physics (PHY121, PHY122) \\
\hline $\begin{array}{c}\text { Engineering Design Process, } \\
\text { Computing Skills (MATLAB, } \\
\text { Excel, etc) }\end{array}$ & Engineering (ENR110, MER250) \\
\hline Trigonometry / Geometry / Algebra & High-school math \\
\hline Systems of Equations & Linear Algebra (MA229, MA265) \\
\hline $\begin{array}{c}\text { Integration and Differentiation, } \\
1^{\text {st }} \text { and } 2^{\text {nd }} \text { order system response }\end{array}$ & Calculus 1 and 2 (MA151, MA152) \\
\hline
\end{tabular}

In terms of instructional setting, our program is small, teaching-focused, and undergraduate-only. Our class sizes are small by design - each classroom is capped at 24 seats, and each lab capped at 12 seats. Our faculty members are expected to focus primarily on teaching and build rapport with students. One-on-one interaction outside of class is very common. These characteristics play a significant role when designing assessment instruments, such as homework assignments, laboratory exercises and, most importantly, design projects.

Another noteworthy, contextual characteristic is that our students spend most of their first two years taking foundational Math, Physics, English, Science and other general university-required liberal arts courses. Therefore, as a program we are constrained to placing Introduction to Circuits in the second semester of junior year. While this is later than at some other institutions 
(where a course like this can be taken at the sophomore or even freshman level), it presents opportunities to cover topics in the context of other Mechanical Engineering subjects. Some examples are fluid flow/pressure analogies, dynamic characteristics of DC motors and application of the design process towards the circuit design project.

While general demographics and academic characteristics of the learners can be important for designing the course, other specific characteristics can also be taken into consideration for making modifications in each offering of the course. For example, for Introduction to Circuits, we ask our students prior to the first class to fill out a "background knowledge probe", through which we collect information about knowledge and skills that students might already possess (i.e., soldering experience, familiarity with measurement instruments, Ohm's Law, Kirchhoff's Laws, etc). Similarly, the students also fill out a "student data sheet" where we try to assess their learning styles and preferences, as well as their expectations from the course. We also ask them to share some personal trivia (i.e., sports, favorite music, movies, etc.) for rapport-building.

\section{d. Write Performance Objectives}

Writing performance objectives is perhaps the best-known step of the SDI process. Depending on the specific field or institution, these may also be known as behavioral objectives, instructional objectives, or course learning outcomes (CLOs), which is our preferred nomenclature. Dick, et al [43], argue that without a model like SDI, it can be difficult to determine how to derive these objectives, and many instructors simply resort to following the outline of a textbook from which to do so. With the SDI process, one should rely on the instructional analysis as the primary source for performance objectives, with a secondary source being the learners-and-contexts analysis.

It is common to express performance objectives using Bloom's Taxonomy of Educational Objectives [45], whose categories, in ascending cognitive level, are: knowledge, comprehension, application, analysis, synthesis, and evaluation. Each cognitive level has a list of "action verbs", which can be used to phrase an individual objective. For our Introduction to Circuits course, the CLOs are listed in Table 3.

Table 3. Introduction to Circuits Course Learning Outcomes (CLOs)

\begin{tabular}{|c|l|}
\hline Number & \multicolumn{1}{|c|}{ Course Learning Outcome } \\
\hline 1 & $\begin{array}{l}\text { Explain the fundamental concepts of electricity and the function of electronic } \\
\text { components. (level: comprehension) }\end{array}$ \\
\hline 2 & $\begin{array}{l}\text { Analyze a basic DC circuit using mathematics and circuit analysis techniques. } \\
\text { (level: analysis) }\end{array}$ \\
\hline 3 & Model and test virtual circuits. (level: application and analysis) \\
\hline 4 & Construct and test circuits on a bread board. (level: application and analysis) \\
\hline 5 & $\begin{array}{l}\text { Design, construct and test a multi-output DC power supply circuit. (level: } \\
\text { synthesis) }\end{array}$ \\
\hline 6 & $\begin{array}{l}\text { Analyze a basic AC circuit using mathematics and circuit analysis techniques. } \\
\text { (level: analysis) }\end{array}$ \\
\hline 7 & Analyze AC/DC motors and generators. (level: analysis) \\
\hline
\end{tabular}


The ABET outcomes associated with the CLOs are listed below. Note that these will have to be updated to reflect the ABET changes that will go into effect for the 2019-20 accreditation cycle.

(a) Ability to apply knowledge of math, science and engineering (CLOs 1-2, 5-7)

(b) Ability to design and conduct experiments, as well as to analyze and interpret data (CLOs 25)

(c) Ability to design a system, component or process to meet desired needs within realistic constraints such as economic, environmental, social, political, ethical, health and safety, manufacturing, and sustainability (CLOs 3-5)

(e) Ability to identify, formulate and solve engineering problems (CLOs 1-7)

(g) Ability to communicate effectively (CLO 5)

(h) Broad education necessary to understand the impact of engineering solutions in a global, economic, environmental, and societal context (CLO 5)

(k) Ability to use techniques, skills and modern engineering tools necessary for engineering practice (CLOs 1-7)

The remaining steps of the forward SDI process (assessment instruments, instructional strategy and materials, and formative evaluation of instruction) are not discussed individually in detail in this paper, but are combined in the results section.

\section{Results: Instructional Strategies, Materials and Assessment Instruments}

As previously mentioned, this course is typically taken in the second semester of junior year, only by Mechanical Engineering students. It consists of a 3-credit classroom portion and a 1credit integrated lab portion. The classroom portion covers basic DC and AC circuit analysis, as well as some other miscellaneous topics like diodes, voltage regulators, motors (DC and AC), generators, and operational amplifiers. The lab focuses on experimental activities related to the course, with an added focus on skills such as soldering and PCB design and layout. The project, which will be detailed hereafter, threads the course to the lab and therefore occupies a mixture of class time and lab time.

\section{Classroom Portion - Lesson Experience}

The classroom portion of the course runs on a Tuesday-Thursday schedule, and therefore consists of a total of 28 75-minute lessons. The topics covered were selected during the Instructional Analysis step of the SDI process, and therefore each supports at least one of the Course Learning Outcomes. A breakdown of lessons in terms of topics/activities is shown in Table 4. The entire course syllabus is in Appendix A. 
Table 4: Lesson Allocation for all Topics and Activities

\begin{tabular}{|l|c|}
\hline \multicolumn{1}{|c|}{ Topic/Activity } & $\begin{array}{c}\text { Number of } \\
\text { Lessons }\end{array}$ \\
\hline $\begin{array}{l}\text { DC Circuit Analysis (Ohm's Law, Kirchhoff's Laws, Resistive } \\
\text { Networks, Node Voltage Analysis, Mesh Current Analysis, } \\
\text { Thévenin Equivalent Circuits, Superposition) }\end{array}$ & 8 \\
\hline Capacitors and RC Circuits & 2 \\
\hline Diodes and Voltage Regulators & 1 \\
\hline DC Motors, Generators and Power Supplies & 2 \\
\hline $\begin{array}{l}\text { AC Circuit Analysis (Phasors, Impedances, Power, } \\
\text { Transformers, AC Motors) }\end{array}$ & 5 \\
\hline Op Amps and 555 Timers & 2 \\
\hline DC Power Circuit Design Project & 4 \\
\hline Exams and Review Sessions & 4 \\
\hline
\end{tabular}

All lessons have been designed to contain a mixture of theory, problem-solving, historical context, and in-class activities and demonstrations. Each individual lesson was developed by first outlining a clear set of Lesson Objectives (LOs). These LOs are expressed in the framework of Bloom's Taxonomy and written in terms of things that the students will be able to do after completion of this particular unit of instruction. The LOs are presented to the students at the beginning of each lesson (often written on the board before the start of class). As an example, the first lesson ("Introduction / Definitions") has the following LOs:

1. Explain course administrative policies

2. Explain why the study of Circuits is important to Mechanical Engineers

3. Define fundamental Circuits terms (charge, current, voltage, power)

4. Measure voltage across and current through a circuit element

5. Calculate power and energy produced or consumed by a circuit element

As with most courses in the School of Engineering at QU, the theory (lecture notes) and problem-solving are planned and executed using a color-schemed "board notes" approach [46]. Our classrooms have (by design) a 10-meter long by 1-meter high chalkboard, subdivided into $101 \mathrm{~m} \mathrm{x} \mathrm{1m} \mathrm{board} \mathrm{units.} \mathrm{Our} \mathrm{lecture} \mathrm{notes} \mathrm{are} \mathrm{therefore} \mathrm{quantized} \mathrm{into} \mathrm{board} \mathrm{units,} \mathrm{and} \mathrm{created}$ using a 'board notes' template. Therefore, the lecture notes for each lesson are arranged in such way that they fit into a specific number of board units, each with a distinct purpose and its contents organized in a consistent color-coordinated way. For example, one may use blue for titles, white for text and numbers, purple for side-notes, green for book equation numbers, etc. Since a full 75-minute lesson rarely requires more than 10 boards, there is seldom the need to erase any portions of the notes within a class, and therefore the entirety of the lecture notes will be on the board by the end. Figure 5 shows an example of a full lesson spanning all 10 boards. This "board notes" approach to lecturing is a central attribute of a 1-week teaching workshop in which all new engineering faculty at QU participate. By choice, most faculty in the School of Engineering have adopted this technique. 


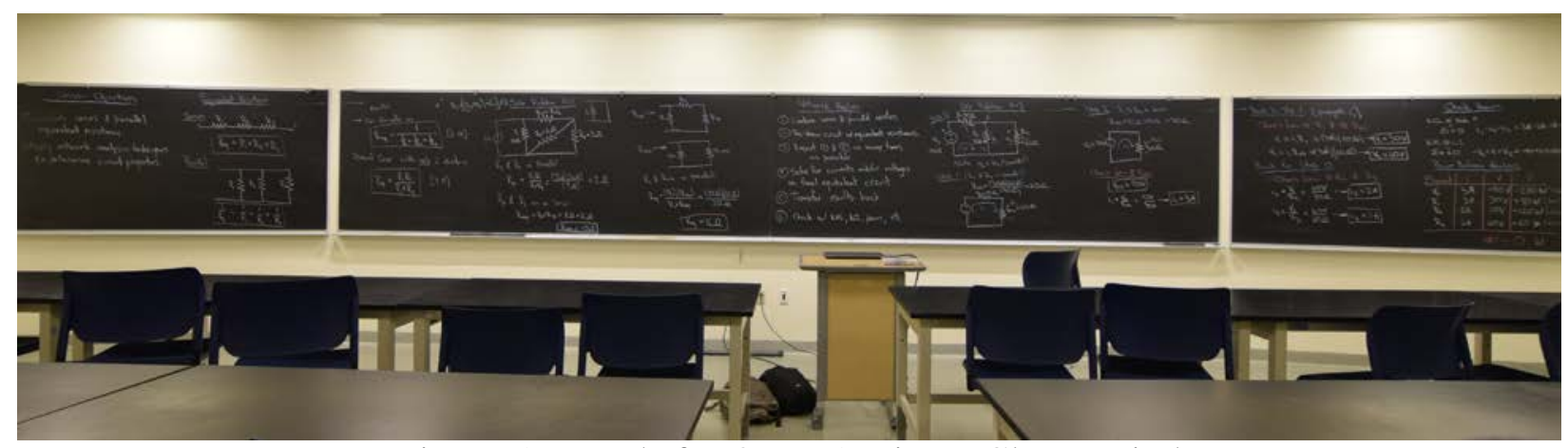

Figure 5: Boards for One 75-Minute Class Period

This first lesson in Introduction to Circuits begins with a hands-on activity in the form of a challenge: each student is given a small light bulb, a AA battery and two Hershey Kisses. The students are then given three minutes to light the bulb. The idea is for them to test their own intuitive knowledge of what makes an electric circuit, and to drive home the point that all of circuit analysis and design is built upon this basic knowledge. After the challenge, a short video is shown to the students in which Mechanical Engineering graduates from an elite US institution are given this very task (with an actual wire instead of chocolate wrappers) and are, in most cases, unsuccessful. One of the graduates in the video who is unable to light the bulb offers the excuse that “...I'm a Mechanical Engineer, not an Electrical Engineer”. It is therefore another goal of this activity to stress the ever-growing importance for Mechanical Engineers to obtain basic electrical knowledge and skills.

In most lessons, we provide some historical context by introducing a "Hero of the Day": a historical figure whose work and legacy are fundamental to the lesson. For example, in the first lesson our hero is Charles Augustin de Coulomb, celebrated for his contributions to electrostatics and electromagnetism, as well as to purely mechanical areas like friction and elasticity. This is a quick segment (less than one minute), and it's aimed to broaden the scope and meaningfulness of the lesson. Table 5 summarizes the instructional design of Lesson 1.

Table 5: Instructional Design of Lesson 1

\begin{tabular}{|l|l|l|l|}
\hline Lesson Objectives & Topics & Hero of the Day & In-Class Activity / Demos \\
\hline - Explain course administrative & - Electric Charge & Charles Augustin & - Hershey Kiss Lightbulb \\
policies & - Electric Current & de Coulomb & Challenge \\
- Explain why the study of Circuits is & and Direction & & - Measuring current and \\
important to Mechanical Engineers & - Voltage and & & voltage with multimeter \\
- Define fundamental Circuits terms \\
$\begin{array}{l}\text { (charge, current, voltage, power). } \\
\text { - Polarity }\end{array}$ & - Power & & \\
- Calculate power and current & & \\
or consumed by a circuit element. & Energy Transfer & & \\
\hline
\end{tabular}

Integrated Lab Portion - Hands-on Experience

Being a new mechanical engineering program, without an electrical engineering department on which to rely for a circuits service course, presented an opportunity to create not only the course content and delivery, but also the actual physical laboratory space and selection of equipment. The lab space would be used for this circuits course and for subsequent courses such as Data 
Acquisition, Mechatronics, and Control Systems (all exclusive to mechanical engineering students). Therefore, special consideration was given to modularity and reusability of equipment. Since there will never be any advanced electrical engineering courses to cater to, there is no need to acquire stand-alone high-performance signal generators, oscilloscopes or other such specialty equipment. Instead, we opted to go with the National Instruments ELVIS II $^{+}$platform as an allin-one instrumentation package.

The ELVIS II+, shown in Figure 6, interfaces with a set of "virtual instruments" (part of a software package) and has extensive input/output functionality. By default, the ELVIS II ${ }^{+}$comes with a breakout board which contains a large general-purpose breadboard and jumper-wire access to all its instruments. Some of these instruments and their capabilities are:

- Digital Multimeter

- $\quad$ Fixed $+5 \mathrm{~V},+15 \mathrm{~V}$ and $-15 \mathrm{~V}$ power supplies

- Positive $(0$ to $+12 \mathrm{~V})$ and Negative $(0$ to $-12 \mathrm{~V})$ variable power supplies

- 2-channel, $100 \mathrm{MS} / \mathrm{s}$ Oscilloscope

- 1-channel, 10 bit Function Generator ( $5 \mathrm{MHz}$ sine, $1 \mathrm{MHz}$ square $\&$ triangle)

- 2-channel, 16-bit, 2MS/s Arbitrary Waveform Generators

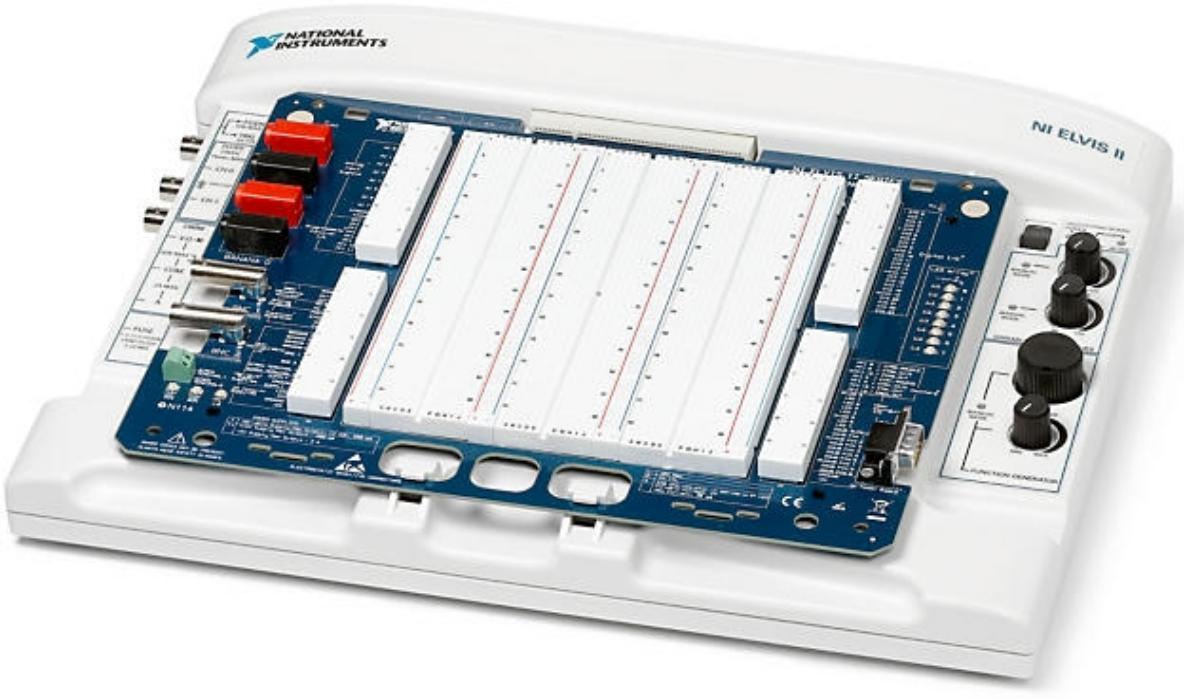

Figure 6: NI ELVIS II $^{+}$Workstation

In addition to the Circuits-related features, the ELVIS II ${ }^{+}$has powerful Analog and Digital I/O capabilities, which, interfaced with LabVIEW, make for a very capable piece of hardware that can be used across the curriculum. Furthermore, other breakout boards for various specific functionalities (made by NI as well as $3^{\text {rd }}$ parties) can be swapped in. For example, the company Quanser makes a variety of breakout boards for very specific Controls and Mechatronics applications, with curricular content cross-linked with the most commonly-adopted textbooks in those areas.

The 600 square-foot laboratory space consists of six student stations and one instructor station. 
Each station accommodates two students (working in pairs) and consists of a PC computer, an ELVIS $\mathrm{II}^{+}$platform, a soldering station, a handheld digital multimeter, a snap-circuits kit, and miscellaneous hand tools. Figure 7 shows an image of the laboratory layout.

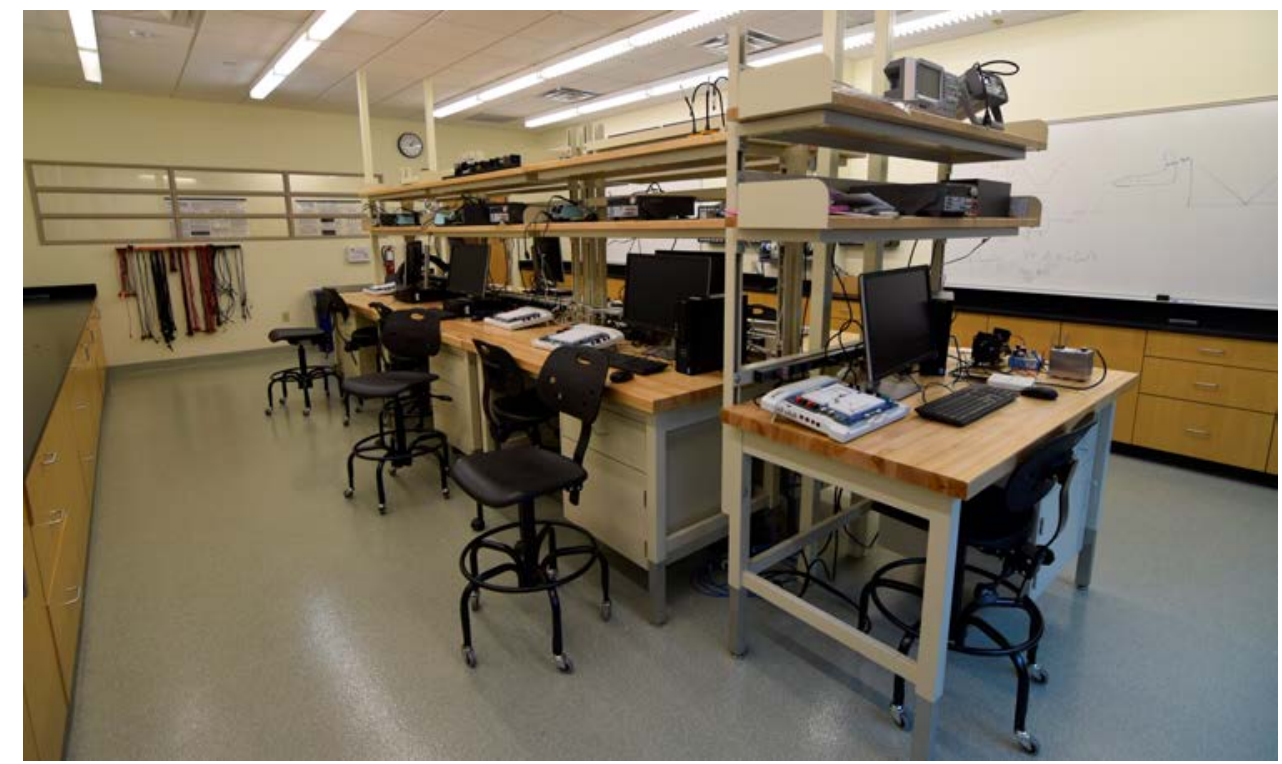

Figure 7: Circuits and Controls Lab at QU

The 1-credit laboratory experience meets once a week for 2 hours. The first lab (on week 1) focuses on the fundamentals of circuit building. The students use Snap Circuits as a precursor step towards breadboarding. This can appeal to visual learners and solidify an intuitive understanding of connecting nodes that is essential when working with breadboards later on. During this Snap Circuits lab, students also learn how to make basic measurements using a handheld digital multimeter, and experientially compare measured values for components arranged in series vs parallel. Subsequent labs utilize the ELVIS $\mathrm{II}^{+}$platform and intertwine with the course, covering most DC circuit analysis topics (Ohm's Law, Kirchhoff's Laws, resistive networks, Node-Voltage Analysis, Thévenin and Norton equivalent circuits) as well as capacitors, RC transients, diodes, voltage regulators, AC circuits and AC transformers. In addition, we use laboratory time to develop hands-on skills such as simulation (using NI Multisim), soldering, and Printed Circuit Board (PCB) design.

\section{Design Project: Multi-Output DC Power Supply}

For the design project in this class, students are given the task to design, simulate, prototype, and fabricate a multi-output DC power circuit. Working in pairs, the students are to follow a prescribed engineering design process (taught earlier in the curriculum), and treat the instructor as the primary customer/stakeholder. In addition, the students are given these specific requirements:

- $\quad$ The circuit must be powered by a $12 \mathrm{~V}$ battery (provided).

- The circuit must have a manual on/off slide-switch incorporated into the circuit board.

- The circuit must have an LED power indicator.

- The circuit must power an electric motor (provided). 
- The circuit must power the kits assembled during the Soldering Lab.

- The circuit must power one other DC device of the students' choosing.

- All connections (power supply, DC motor, soldering lab kit, extra DC device) must be done via screw terminals.

- The circuit should be able to run for 4 hours without replacing or recharging the battery, assuming that the motor will run $60 \%$ of the total run time.

- The circuit must be embodied in a PCB using through-hole components.

The project is performed in stages. The first stage consists of problem definition, preliminary design, simulation (using Multisim) and energy budget analysis. The second stage consists of prototyping and testing (on a breadboard, using ELVIS), creating and ordering PCBs, and submitting a full Bill of Materials (assuming a 4,000 unit production run). For the third and final stage, students assemble and test their PCBs (soldering), and showcase their final product. This project has been largely successful, and all students to date have produced good working power supply circuits. Figure 8 shows an example of a submitted PCB layout file and its corresponding populated embodiment.
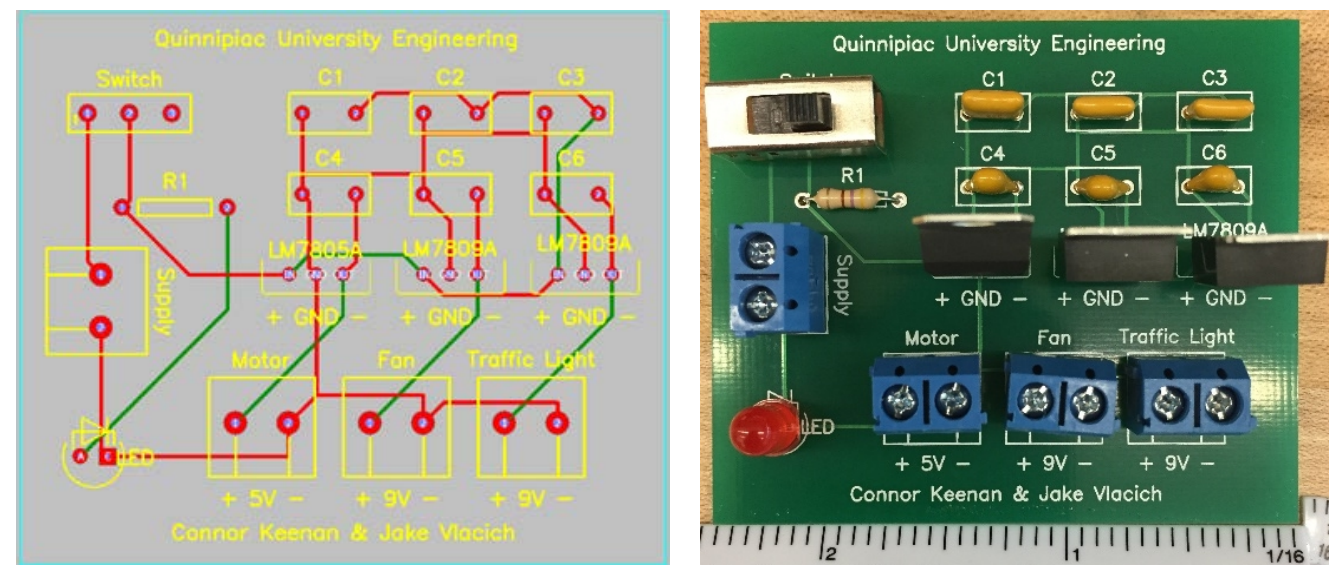

Figure 8: Submitted Multi-Output DC Power Supply Circuit. PCB Layout (left) and Populated Circuit Board (right)

While these circuits are somewhat simple, the positive impact of the applied knowledge obtained by this project has been evident not only in the course evaluations, but also (and most importantly) by the successful application of PCB circuit design in senior capstone design projects. Given the mechatronic nature of many such capstone projects, this skillset has empowered students to take ownership of the quality of the electronic portions of their designs. For instance, one capstone team designed a self-balancing 2-wheeled transport device, which required instrumentation circuitry for various sensors, control inputs and motor drive signals. Using the skills learned in this circuits course, they designed and fabricated a PCB to house these relatively complex electronics. This circuit board is shown in Figure 9, in its multiple stages from design to implementation. 

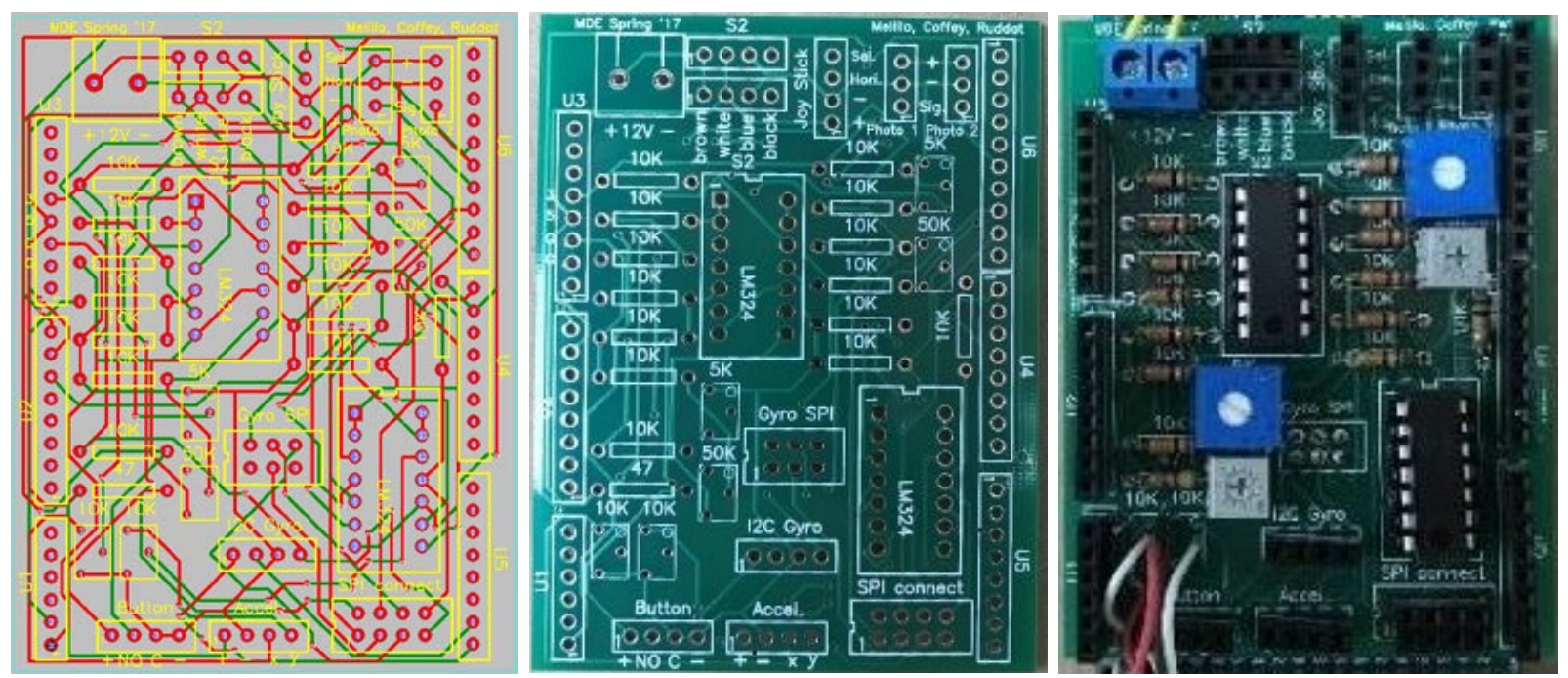

Figure 9: Senior Capstone Electronics Board.

PCB Layout (left), Unpopulated Board (middle) and Populated Board (right)

\section{Assessment and Evaluation}

The resulting Course Learning Outcomes (CLOs) developed for QU's introductory circuits course are listed in Table 3. These are achieved through the SDI-designed collection of presentations, exercises, labs, experiences, etc. These activities are collected into lessons, each with its own set of lesson objectives. The primary lesson and lab topics and their sequence is specified in the course syllabus which is included in Appendix A.

Following each semester, the faculty member teaching the course conducts a CLO assessment using a course assessment matrix tool [44]. This assessment involves mapping selected graded events in the course to the CLOs and results in an evaluation of the level of achievement of each. This evaluation result is in the form of a rating based on a 5-point Likert scale and is a measure of whether or not the students have met the CLO. The Likert scale ratings are shown in Table 6 .

Table 6. Likert Scale Ratings

\begin{tabular}{|c|c|}
\hline Rating & Associated Meaning \\
\hline 1 & Strongly Disagree \\
\hline 2 & Disagree \\
\hline 3 & Neither Agree nor Disagree \\
\hline 4 & Agree \\
\hline 5 & Strongly Agree \\
\hline
\end{tabular}

This direct measure of CLO achievement is compared to an indirect assessment collected via an end-of-course student survey. The student survey measures the students' perception of their ability to achieve each CLO. The assessment uses the same 5-point Likert scale and is compared to the results of the course assessment matrix tool. The evaluation of CLOs for the spring of 2016 course offering is shown in Figure 10. 


\section{Course Learning Outcomes, SP16}

1. Explain the fundamental concepts of electricity and the function of electronic components.

2. Analyze a basic DC circuit using mathematics and circuit analysis techniques.

3. Model and test virtual circuits.

4. Construct and test circuits on a bread board.

5. Design, construct and test a multi-output DC power supply circuit.

6. Analyze a basic AC circuit using mathematics and circuit analysis techniques.

7. Analyze AC/DC Motors and Generators.

- Indirect Assessment (student survey)

$\square$ Direct Assessment (course assessment matrix)

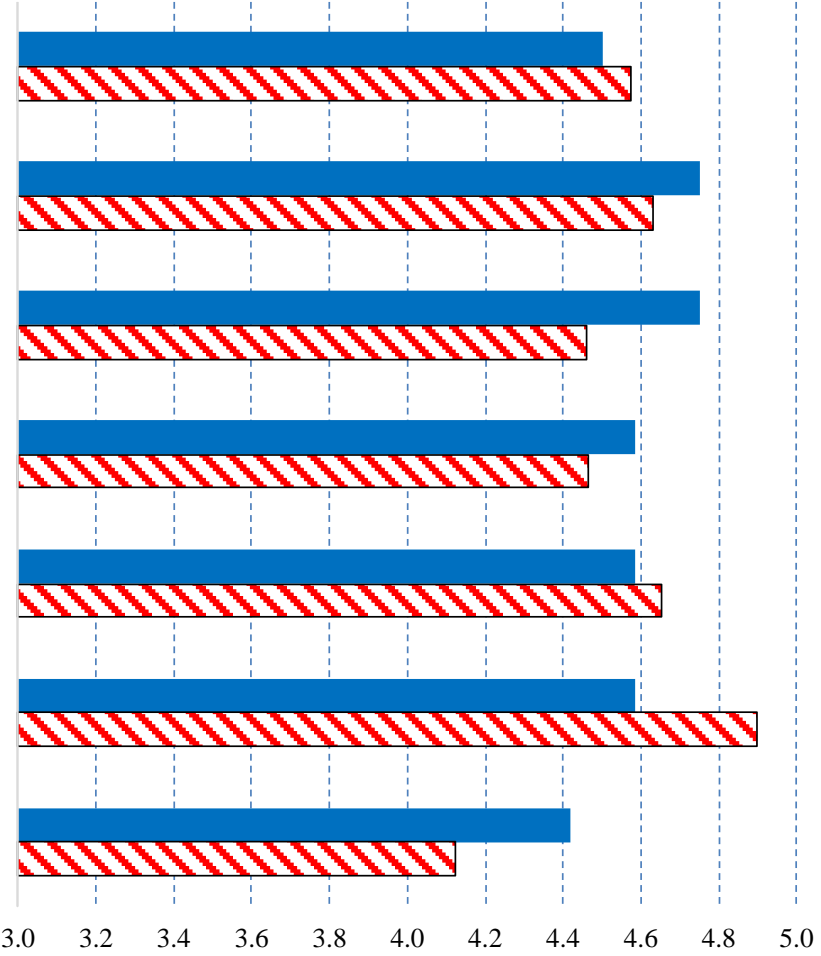

Figure 10. Course Objective Evaluation for Spring 2016

Through a separate internal study, we have found a very strong correlation between these two (direct and indirect) assessment tools. We looked at all the CLOs in the entire ME program in a given year (about 100 total), and for each CLO we compared the direct assessment (weighted average grade of all graded work corresponding to that objective, converted to 5-point Likert scale) to the indirect assessment (average response from student survey, also in 5-point Likert scale). The deviation between the two (indirect minus direct) is a number with a possible range of [-4...4], where a positive number indicates a sense of over-confidence of students' selfassessment with respect to their objective performance, and vice-versa. We tallied up the deviations from all the CLOs, and obtained a normal distribution centered at +0.1 (2.5\% overconfidence), with a standard deviation of 0.28 (7\%). This distribution is shown in Figure 11 . This means that while students tend to have a slight overconfidence in their own abilities, it is so by a very small margin and therefore a reliable correlation exists. 


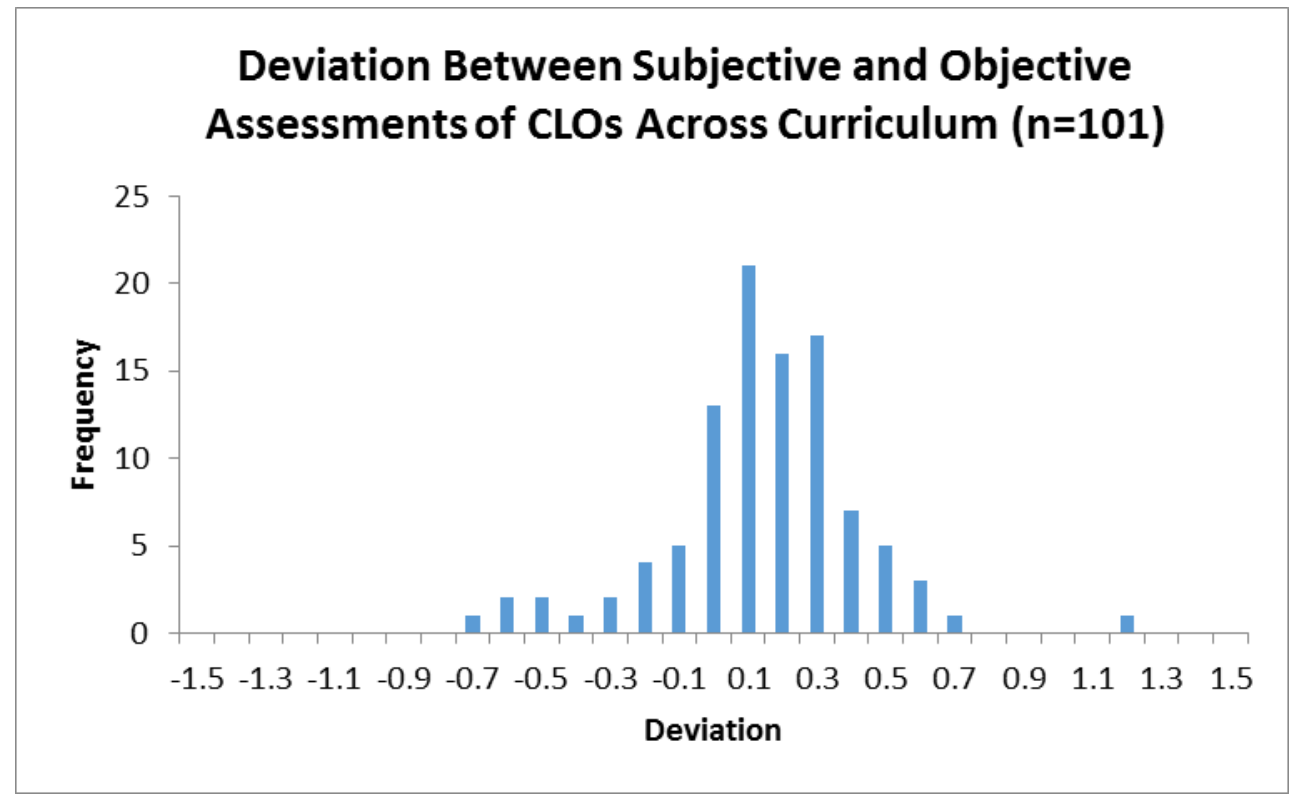

Figure 11: Deviation between Subjective and Objective CLO Assessments

For this paper, the authors developed a more focused, anonymous survey (Appendix B) to assess student perceptions of their circuit-related abilities at least six-months after completing their circuits course. The survey was given to mechanical engineering students at QU and students at a nationally-regarded, peer institution. A comparison of the two institutions is shown in Table 7. The circuits course syllabus for the peer institution is included for reference in Appendix C.

Table 7. Comparison of Surveyed Institutions

\begin{tabular}{|c|c|c|}
\hline Metric & Quinnipiac University & Peer Institution \\
\hline ME Program Level & BS Only & BS Only \\
\hline US News Ranking* & NA & $\# 5$ \\
\hline $\begin{array}{c}\text { Institution Undergrad } \\
\text { Enrollment }\end{array}$ & 6,600 & 4,400 \\
\hline $\begin{array}{c}\text { Circuit Course } \\
\text { Taught By }\end{array}$ & $\begin{array}{c}\text { Mechanical Engineering } \\
\text { Program }\end{array}$ & $\begin{array}{c}\text { Electrical Engineering } \\
\text { Program }\end{array}$ \\
\hline $\begin{array}{c}\text { Circuits Course } \\
\text { Serves }\end{array}$ & Mechanical Engineers & $\begin{array}{c}\text { Electrical Engineers } \\
\text { Mechanical Engineers } \\
\text { Nuclear Engineers }\end{array}$ \\
\hline Students Surveyed & Seniors & Seniors \\
\hline $\begin{array}{c}\text { Survey Sample } \\
\text { \# sampled/class size) }\end{array}$ & $19 / 19$ & $17 / 85$ \\
\hline
\end{tabular}

*ME programs at institutions without a doctorate

The students surveyed at the peer institution were volunteers (self-selecting) and represented $20 \%$ of the senior class of mechanical engineering majors. The students reported their cumulative GPAs by selecting a GPA band in which they fell (e.g. 3.51-3.75, 3.76-4.00, etc.). To have a better understanding of the composition of the volunteer group from the peer institution, the authors calculated the overall 'minimum' GPA for this group by taking the floor of each selected GPA band for these students. The overall GPA for this group was calculated as 
a minimum of 3.60 and compared to the entire class' GPA of 3.35 which was available from the peer institution. The authors concluded that the self-select group from the peer institution represents the higher level performers for the institution and constitutes a useful comparison group.

Data from the QU and peer institution groups was collected for each question and a simple average Likert score was computed for each question. The comparison of average scores from the two programs is shown in Figure 12.

\section{Program Comparison}

I can explain the fundamental concepts of electricity (e.g. current, voltage, and power) and the function of electronic components (e.g. resistors, capacitors, diodes). I can analyze a DC circuit using various circuit analysis techniques (e.g. Ohm's law, Kirchhoff's voltage law, and Kirchhoff's current law, node voltage analysis, mesh...

I can simulate, model, and test virtual circuits using computer software (e.g. Multisim, PSpice, etc.).

I can construct and test circuits on a breadboard.

I can design a multi-output DC power supply circuit that could be used in a mechatronic/robotic device. This includes sizing of the input power source,...

I can design a printed circuit board (PCB) layout for a multi-output DC power supply circuit.

I can construct a multi-output DC power supply circuit. This includes the soldering of wires, connectors and components onto the printed circuit board.

I can test a multi-output DC power supply circuit. This includes verifying the functionality of all powered components and the correct power output of all DC..

$\square$ Our Institution
@Peer
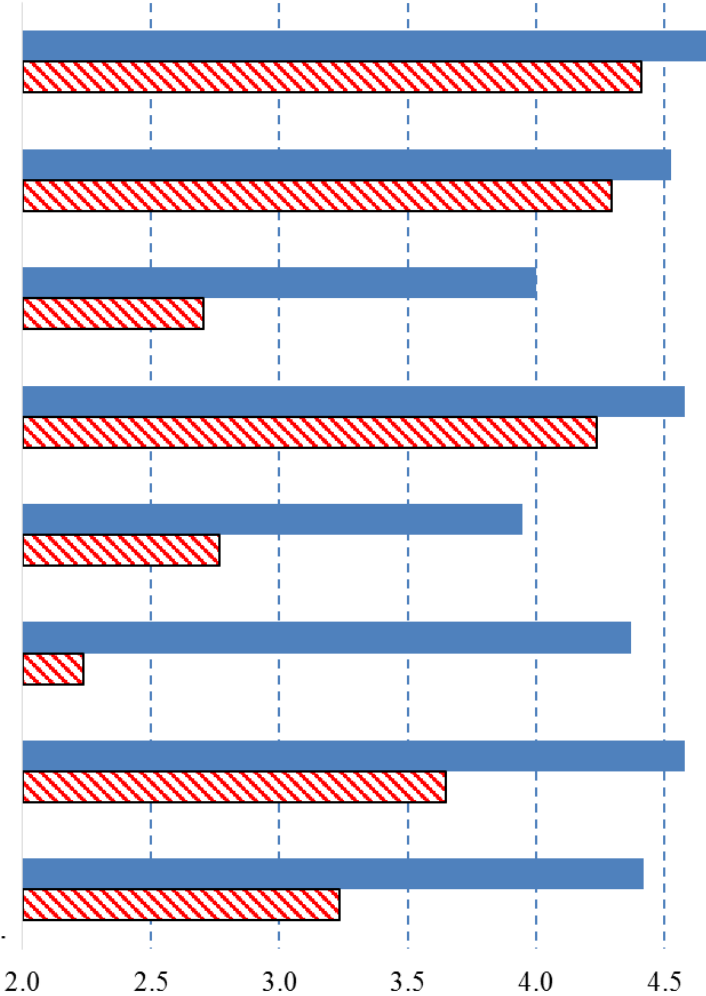

Figure 12. Comparison of Student Perceptions from Two ME Programs

Results indicate that the QU students are significantly more confident in their ability to simulate and test virtual circuits. They are also more confident in their ability to design a multi-output, DC power supply and design the custom printed circuit board for their designs. All of these are key aspects of our circuit design process which is integrated into the course and its lab. This is not a measure of better students or better teaching, but a measure of the successful application of the SDI process to design a course and lab structure that integrates effective learning activities to achieve the desired results. The QU mechanical engineering CLOs for the circuits course are different than the those for the peer program's circuit course. Using SDI to design a course to meet our specific needs allowed our students to achieve our objectives at a higher level than a using the syllabus from a circuits course designed for a different purpose and population. 
The learning outcomes of QU's circuits course are not necessarily applicable to other programs and the results achieved by this course should not be taken to mean that all circuits courses should adopt its syllabus and content. Each program has unique needs based on the composition of its constituents.

\section{Conclusion}

When developing the Introduction to Circuits course for the new engineering school at Quinnipiac University, there were two fundamental options open to the faculty. One was to use a course from another institution with which the faculty were familiar and which was known to be a 'successful' course. The other was to purposely develop a course that was focused on meeting the specific objectives of the mechanical engineering program and its constituents and that dovetailed with the other courses and experiences in the curriculum.

Opting for the second option and using the Systematic Design of Instruction process, the resulting course achieved the program objectives at a higher level than a course used at a comparative institution. As verified by objective course evaluation data and the correlating student perception data, the new course provides students with foundational knowledge in DC and AC circuits, circuit design fundamentals, and foundational knowledge for future courses in Mechatronics, Controls, and Data Acquisition. Not only do students achieve all course objectives at a high level, they are also able to display their course content proficiency in their subsequent senior capstone projects.

\section{References}

[1] "Best Undergraduate Engineering Programs (Doctorate)," U.S. News and World Report, 2017. [Online]. Available: https://www.usnews.com/best-colleges/rankings/engineeringdoctorate. [Accessed Nov. 27, 2017].

[2] "Best Undergraduate Engineering Program Rankings (No doctorate)," U.S. News and World Report, 2017. [Online]. Available: https://www.usnews.com/bestcolleges/rankings/engineering-overall. [Accessed Nov. 27, 2017].

[3] “Engineering Curriculum,” Harvey Mudd College, 2017. [Online]. Available: https://www.hmc.edu/engineering/curriculum/courses/engineering-course-descriptions/\#84. [Accessed Nov. 30, 2017].

[4] “ES 203 Electrical Systems, Course Syllabus,” Rose-Hulman Institute of Technology, 2017. [Online]. Available: https://www.rosehulman.edu/ berry123/Courses/ES203/ES203_Syllabus.pdf. [Accessed Nov. 27, 2017].

[5] “Mechanical Engineering (ME)," Franklin W. Olin College of Engineering, 2017. [Online]. Available: http://olin.smartcatalogiq.com/en/2017-18/Catalog/Programs-of-Study-andDegree-Requirements/Academic-Programs/Mechanical-Engineering-ME. [Accessed Nov. 28, 2017].

[6] “Class of 2019: Mechanical Engineering Major (MEN1),” United States Military Academy, 2017. [Online]. Available: https://www.usma.edu/cme/SiteAssets/SitePages/Mechanical \%20Engineering\%20Major/Templates\%202019\%20-\%2008MAR16.pdf. [Accessed Nov. 27, 2017]. 
[7] “MECHANICAL ENGINEERING MAJOR,” United States Air Force Academy, 2017. [Online]. Available: https://www.academyadmissions.com/wpcontent/uploads/2012/05/Courses_MechanicalEngineering.pdf. [Accessed Nov. 27, 2017].

[8] “Mechanical Engineering Matrix 2015,” United States Naval Academy, 2017. [Online]. Available: https://www.usna.edu/MechEngDept/students/me_matrix.php. [Accessed Nov. 27, 2017].

[9] “Mechanical Engineering (MECH),” Bucknell University, 2017. [Online]. Available: http://coursecatalog.bucknell.edu/collegeofengineeringcurricula/areasofstudy/mechanicalen gineeringmech/\#majortext. [Accessed Nov. 28, 2017].

[10] "BS Mechanical Engineering," California Polytechnic State University -- San Luis Obispo, 2017. [Online]. Available:

http://catalog.calpoly.edu/collegesandprograms/collegeofengineering/mechanicalengineerin g/bsmechanicalengineering/. [Accessed Nov. 28, 2017].

[11] “Curriculum - Mechanical Engineering,” Cooper Union, 2017. [Online]. Available: https://cooper.edu/engineering/mechanical-engineering/curriculum. [Accessed Nov. 28, 2017].

[12] "Mechanical Engineering, B.S.,” Milwaukee School of Engineering, 2017. [Online]. Available: http://catalog.msoe.edu/preview_program.php?catoid=16\&poid= 818\&returnto=442. [Accessed Nov. 28, 2017].

[13] “Mechanical Engineering Curriculum by Year,” United States Coast Guard Academy, 2017. [Online]. Available: http://www.uscga.edu/academics2.aspx?id=365. [Accessed Nov. 28, 2017].

[14] “Curriculum - Mechanical Engineering,” Lafayette College, 2017. [Online]. Available: https://me.lafayette.edu/curriculum/. [Accessed Nov. 28, 2017].

[15] "Mechanical Engineering Major,” University of San Diego, 2017. [Online]. Available: https://www.sandiego.edu/engineering/programs/mechanical-engineering/curriculum.php. [Accessed Nov. 28, 2017].

[16] "California State Polytechnic University, Pomona Degree Curriculum Sheet," California Polytechnic State University - Pamona, 2017. [Online]. Available: http://www.cpp.edu/ engineering/current/currsheets/curricsheets/2015-16/ME/me_1516.pdf. [Accessed Nov. 28, 2017].

[17] "Bachelor of Science in Mechanical Engineering," Embry-Riddle Aeronautical University Prescott, 2017. [Online]. Available: http://prescott.erau.edu/degrees/bachelor/mechanicalengineering/index.html. [Accessed Nov. 28, 2017].

[18] “Mechanical Engineering,” Kettering University, 2017. [Online]. Available: http://catalog.kettering.edu/undergrad/academic-programs/mechanicalengineering/\#curriculumtext. [Accessed Nov. 28, 2017].

[19] "Bachelor of Science in Engineering Science," Smith College, 2017. [Online]. Available: https://www.smith.edu/engineering/bs.php. [Accessed Nov. 28, 2017].

[20] “Mechanical Engineering,” Valparaiso University, 2017. [Online]. Available: https://www.valpo.edu/college-of-engineering/academics/undergraduate/mechanicalengineering/. [Accessed Nov. 28, 2017].

[21] "Mechanical Engineering Program,” The Citadel, 2017. [Online]. Available: http://www.citadel.edu/root/images/mechanical_engineering/2017_2018_me_ug_rev\%209 aug2017.pdf. [Accessed Nov. 28, 2017]. 
[22] "Mechanical Engineering," Gonzaga University, 2017. [Online]. Available: https://www.gonzaga.edu/catalogues/17-18-catalogue/undergraduate/school-ofengineering/mechanical-engineering.asp. [Accessed Nov. 28, 2017].

[23] “Mechanical Engineering (Course 2),” Massachusetts Institute of Technology, 2017. [Online]. Available: http://catalog.mit.edu/degree-charts/mechanical-engineering-course-2/. [Accessed Nov. 30, 2017].

[24] “HANDBOOK FORUNDERGRADUATE ENGINEERINGPROGRAMS,” Stanford University, 2017. [Online]. Available: https://stanford.app.box.com/s/frvfj1d8zjl3da8yl goa1eij6oxgb29b. [Accessed Nov. 30, 2017].

[25] “Mechanical Engineering Undergraduate Curriculum,” University of California - Berkeley, 2017. [Online]. Available: http://www.me.berkeley.edu/sites/default/files/undergraduate/ CurriculumFlowchart.pdf. [Accessed Nov. 30, 2017].

[26] “Recommended Course Schedule,” California Institute of Technology, 2017. [Online]. Available: https://d39s7jey1vv9fu.cloudfront.net/mce/documents/CourseSchedules.pdf. [Accessed Nov. 30, 2017].

[27] “ME Undergraduate Curriculum (Catalog: 2017 - 2018),” Georgia Institute of Technology, 2017. [Online]. Available: http://www.me.gatech.edu/files/ug/program_of_study_ me1718.pdf. [Accessed Nov. 30, 2017].

[28] "Bachelor of Science in Mechanical Engineering," University of Illinois -- UrbanaChampaign, 2017. [Online]. Available: http://catalog.illinois.edu/undergraduate/engineer/ departments/mech-engin/bs-mechanical-engineering/. [Accessed Nov. 30, 2017].

[29] “BACHELOR'S DEGREE,” University of Michigan - Ann Arbor, 2017. [Online]. Available: https://me.engin.umich.edu/academics/undergrad/handbook/bachelors. [Accessed Nov. 30, 2017].

[30] “Department of Mechanical Engineering,” Carnegie Mellon University, 2017. [Online]. Available: http://coursecatalog.web.cmu.edu/carnegieinstituteoftechnology /departmentofmechanicalengineering/\#curriculumtext. [Accessed Nov. 30, 2017].

[31] “Mechanical Engineering Program Map,” Purdue University -- West Lafayette, 2017. [Online]. Available: https://engineering.purdue.edu/ME/Academics/Undergraduate /ProgramMap. [Accessed Nov. 30, 2017].

[32] "Bachelor of Science, Mechanical Engineering Degree Requirements," Cornell University, 2017. [Online]. Available: http://www.mae.cornell.edu/mae/academics/undergrad/ memajor/index.cfm. [Accessed Nov. 30, 2017].

[33] "DEPARTMENT OF MECHANICAL AND AEROSPACE ENGINEERING UNDERGRADUATE PROGRAMS,” Princeton University, 2017. [Online]. Available: http://mae.princeton.edu/sites/default/files/MAE-UG-HANDBOOK-2014-2015-EffectiveClass-2017-Fall-2014-Edition-V7-WEBVersion.pdf. [Accessed Nov. 30, 2017].

[34] “2016 - 2018 Undergraduate Catalog General Curriculum,” University of Texas - Austin, 2017. [Online]. Available: http://www.me.utexas.edu/images/undergrad2016-18.pdf. [Accessed Nov. 30, 2017].

[35] “BS CURRICULUM,” Northwestern University, 2017. [Online]. Available: http://www.mccormick.northwestern.edu/mechanical/undergraduate/curriculum/. [Accessed Nov. 30, 2017].

[36] "Mechanical Engineering major - Course Dependency Map - Classes of 2018-19-20," Johns Hopkins University, 2017. [Online]. Available: https://me.jhu.edu/wp- 
content/uploads/sites/38/2017/07/ME-Course-Dependency-Map-Class-of-2018-19-20.pdf. [Accessed Nov. 30, 2017].

[37] "Bachelor of Science," Texas A\&M University - College Station, 2017. [Online]. Available: https://engineering.tamu.edu/mechanical/academics/degrees/undergraduate/bs. [Accessed Nov. 30, 2017].

[38] “MECHANICAL ENGINEERING, B.S.,” University of Wisconsin - Madison, 2017. [Online]. Available: http://guide.wisc.edu/undergraduate/engineering/mechanicalengineering/mechanical-engineering-bs/\#fouryearplantext. [Accessed Nov. 30, 2017].

[39] "Bachelor of Science in Mechanical Engineering," Virginia Tech, 2017. [Online]. Available: https://registrar.vt.edu/content/dam/registrar_vt_edu/documents/Updates /coe/COE_me_18.pdf. [Accessed Nov. 30, 2017].

[40] "Program Requirements,” Columbia University, 2017. [Online]. Available: http://me.columbia.edu/program-requirements. [Accessed Nov. 30, 2017].

[41] “B.S. in Mechanical Engineering Curriculum,” University of California - Los Angeles, 2017. [Online]. Available: http://www.seasoasa.ucla.edu/curric-17-18/38curmech-17.html. [Accessed Nov. 30, 2017].

[42] “BSE Degree Planning,” Duke University, 2017. [Online]. Available: http://mems.duke.edu/undergrad/degrees/planning. [Accessed Nov. 30, 2017].

[43] W. Dick, L. Carey, and J. Carey, The Systematic Design of Instruction, eighth edition. New York, NY: Pearson, 2015.

[44] B. Crawford, "Using Student Performance and Faculty Experience to Assess a Mechanical Engineering Program,” Paper AC 2007-1372, American Society for Engineering Education Annual Conference, Honolulu, HI, USA, June 24-27, 2007.

[45] B. Bloom, M Engelhart, W. Hill, E. Furst and D. Krathwohl, Taxonomy of Educational Objectives, Handbook I: Cognitive Domain, New York, NY, David McKay Company, 1956.

[46] S. Ressler, R. Welch and K.Meyer, "Organizing and Delivering Classroom Instruction," Journal of Professional Issues in Engineering Education and Practice, American Society of Civil Engineers, July 2004, pp 153-156. 


\section{Appendix A: QU Introductory Circuits Course Syllabus}

\begin{tabular}{|c|c|c|c|c|c|c|c|}
\hline Day & Date & Block & LSN & Topic & Assignment & Assigned & Due \\
\hline Tue. & 23-Jan & \multirow{6}{*}{ DC Electricity } & 1 & Introduction - Definitions, Voltage, Current, Power and Energy & $\begin{array}{l}\text { Scan: Sec } 1.1 \\
\text { Read: Sec } 1.2 \& 1.3\end{array}$ & HW 1 & \\
\hline Thurs. & 25-Jan & & 2 & Kirchhoff's Laws & Read: Sec 1.4 \& 1.5 & & \\
\hline \multicolumn{2}{|c|}{ Week 1 Lab } & & A & Lab - Safety Orientation, Snap Circuits Lab & & & \\
\hline Tue. & 30-Jan & & 3 & Circuit Elements 1 - Sources, Resistors and Ohm's Law & Read: 1.6 & $\mathrm{HW} 2$ & HW 1 \\
\hline Thurs. & 1-Feb & & 4 & Circuit Analysis 1 - Resistive Circuits & $\begin{array}{l}\text { Read: 1.7, 2.1, 2.2, } \\
2.3\end{array}$ & & \\
\hline \multicolumn{2}{|c|}{ Week 2 Lab } & & B & Lab - Bread Boards and Elvis II+ Introduction & & & Lab A \\
\hline Tue. & 6-Feb & \multirow{7}{*}{$\begin{array}{c}\text { Basic } \\
\text { DC Circuits }\end{array}$} & 5 & Circuit Analysis 2 - Node Voltage Analysis \& MATLAB & Read: 2.4 & HW3 & HW2 \\
\hline Thurs. & 8-Feb & & 6 & Circuit Analysis 3 - Mesh Current Analysis & Read: 2.5 & & \\
\hline \multicolumn{2}{|c|}{ Week 3 Lab } & & $\mathbf{C}$ & Lab - MultiSim and Node Voltage Analysis & & & Lab B \\
\hline Tue. & 13-Feb & & 7 & Circuit Elements 2 - Capacitors and Capacitance & $\begin{array}{l}\text { Read: 3.1, 3.2, 3.3, } \\
4.1\end{array}$ & HW4 & HW3 \\
\hline Thurs. & 15-Feb & & 8 & RC Circuits and 1st-order transients & & & \\
\hline Week & k 4 Lab & & D & Lab - Capacitors and RC Circuits & & & Lab C \\
\hline Tue. & $20-\mathrm{Feb}$ & & 9 & Exam \#1 - Basic DC Circuits & Review All Previous & & HW4 \\
\hline Thurs. & $22-\mathrm{Feb}$ & \multirow{8}{*}{$\begin{array}{l}\text { Advanced } \\
\text { DC Circuits }\end{array}$} & 10 & Thevenin Equivalent Circuits & Read:2.6 & HW5 & \\
\hline Week & k 5 Lab & & $\mathbf{E}$ & Lab - Solder Lab & & & Lab D \\
\hline Tue. & $27-F e b$ & & 11 & Circuit Analysis 4 - Wheatstone Bridge and Superposition & Read: $2.7,2.8$ & & \\
\hline Thurs. & 1-Mar & & 12 & Diodes and Voltage Regulators & Read: $10.1-10.5$ & HW6 & HW5 \\
\hline \multicolumn{2}{|c|}{ Week 6 Lab } & & $\mathbf{F}$ & Lab - Equivalent Circuits (Thevenin and Norton) & & & Lab E \\
\hline Tue. & 6-Mar & & 13 & DC Devices 1 - Motors & Read:16.1 - 16.6 & & \\
\hline Thurs. & 8-Mar & & 14 & DC 2 - Generators and Battery Power | DC Power Design 1 - Requiremen & Read: 16.7 & Design & HW6 \\
\hline \multicolumn{2}{|c|}{ Week 7 Lab } & & $\mathbf{G}$ & Lab - Diodes \& Voltage Regulators & & & Lab F \\
\hline \begin{tabular}{|l|l} 
Tue. & \\
\end{tabular} & 13-Mar & \multirow{2}{*}{\multicolumn{6}{|c|}{ Spring Break! }} \\
\hline Thurs. & 15-Mar & & & & & & \\
\hline \begin{tabular}{|l|l} 
Tue. & \\
\end{tabular} & 20-Mar & \multirow{7}{*}{$\begin{array}{l}\text { DC Circuit } \\
\text { Design }\end{array}$} & 15 & DC Power Design 2 - Circuit Design 1 & TBD & & \\
\hline Thurs. & 22-Mar & & 16 & DC Power Design 3 - Circuit Design 2 & TBD & & \\
\hline \multicolumn{2}{|c|}{ Week 8 Lab } & & & DC Power Circuit Design - Multisim Simulation & & & $\begin{array}{c}\text { Design A } \\
\text { Lab G } \\
\end{array}$ \\
\hline Tue. & 27-Mar & & 17 & DC Power Design 4 - PCB Design & TBD & & \\
\hline Thurs. & 29-Mar & & 18 & DC Power Circuit Design - Circuit Prototype and Test, PCB Order & TBD & & \\
\hline \multicolumn{2}{|c|}{ Week 9 Lab } & & & No Lab - Easter Friday & & & Design $\mathrm{B}$ \\
\hline Tue. & 3-Apr & & 19 & Exam \#2 - DC Circuit Analysis & & & \\
\hline Thurs. & 5-Apr & \multirow{9}{*}{ AC Electricity } & 20 & AC Circuits 1 - Voltage and Current & Read: $5.1-5.4$ & $\mathrm{HW} 7$ & \\
\hline \multicolumn{2}{|c|}{ Week 10 Lab } & & $\mathbf{H}$ & Lab - Experiential AC Learning Lab & & & \\
\hline Tue. & 10-Apr & & 21 & AC Circuits 2 - Phasors and Impedances & Read: $5.5-5.6$ & & \\
\hline Thurs. & 12-Apr & & 22 & AC Circuits 3 - Power and Energy & Read: $5.5-5.6$ & HW 8 & $\mathrm{HW} 7$ \\
\hline \multicolumn{2}{|c|}{ Week 11 Lab } & & 1 & Lab - AC Transformer Lab & & & Lab H \\
\hline \begin{tabular}{|l|l} 
Tue. \\
\end{tabular} & 17-Apr & & 23 & PCB Build & & & \\
\hline Thurs. & 19-Apr & & 24 & AC Circuits 4 - Transformers and Faraday's Law & Read: 15.1 - 15.6 & & \\
\hline \multicolumn{2}{|c|}{ 17:B39A1:B39A } & & & DC Power Circuit Design - PCB Build \& Test & & & Lab I \\
\hline Tue. & 24-Apr & & 25 & AC Circuits 5 - AC Motors & Read: 17.1 - 17.5 & HW 9 & HW 8 \\
\hline Thurs. & 26-Apr & \multirow{5}{*}{ Special Topics } & 26 & Op Amps 1 & $\begin{array}{l}\text { Read: } 14.0-14.2 \\
\text { (skip start of } 14.1 \text { ) }\end{array}$ & HW 8 & Design Rpt \\
\hline \multicolumn{2}{|c|}{ Week 13 Lab } & & & DC Power Circuit Design Presentation & & & \\
\hline Tue. & 1-May & & 27 & Op Amps 2 and 555 Timers & Read: $14.1,14.3$ & & \\
\hline Thurs. & 3-May & & 28 & Review & TBD & & HW 9 \\
\hline \multicolumn{2}{|c|}{ Week 14 Lab } & & & Lab - Problem Solving - Prep for Final Exam & & & \\
\hline Thurs. & 10-May & & & Final Exam - 10:30 am & & & \\
\hline
\end{tabular}




\section{Appendix B: Anonymous Circuits Knowledge Survey}

1. What is your current cumulative GPA? (circle one)
$3.75-4.00$
$2.50-2.74$
$3.50-3.74$
$2.25-2.49$
$3.25-3.49$
$2.00-2.24$
$3.00-3.24$
$<2.00$
$2.75-2.99$

2. When did you take your circuits course? (circle one)

Spring, 2016

Fall, 2016

Spring, 2017

Answer the following questions by circling the appropriate response:

3. I can explain the fundamental concepts of electricity (e.g. current, voltage, and power) and the function of electronic components (e.g. resistors, capacitors, diodes).
Strongly Agree
Agree
Neutral
Disagree
Strongly Disagree

4. I can analyze a DC circuit using various circuit analysis techniques (e.g. Ohm's law, Kirchhoff's voltage law, and Kirchhoff's current law, node voltage analysis, mesh current analysis, etc.).
Strongly Agree
Agree
Neutral
Disagree
Strongly Disagree

5. I can simulate, model, and test virtual circuits using computer software (e.g. Multisim, PSpice, etc.).
Strongly Agree
Agree
Neutral
Disagree
Strongly Disagree

6. I can construct and test circuits on a breadboard.

Strongly Agree

Agree

Neutral

Disagree

Strongly Disagree 
7. I can design a multi-output DC power supply circuit that could be used in a mechatronic/robotic device. This includes sizing of the input power source, identification of power needs for all powered components, and selection of the appropriate circuit components.

$\begin{array}{llll}\text { Strongly Agree } & \text { Agree } & \text { Neutral } & \text { Disagree }\end{array}$

8. I can design a printed circuit board (PCB) layout for a multi-output DC power supply circuit.

Strongly Agree $\quad$ Agree Neutral Disagree Strongly Disagree

9. I can construct a multi-output DC power supply circuit. This includes the soldering of wires, connectors and components onto the printed circuit board.

$\begin{array}{llll}\text { Strongly Agree } & \text { Agree } & \text { Neutral } & \text { Disagree }\end{array}$

10. I can test a multi-output DC power supply circuit. This includes verifying the functionality of all powered components and the correct power output of all DC power nodes.
Strongly Agree
Agree
Neutral
Disagree
Strongly Disagree 


\section{Appendix C: Peer Institution Circuits Course Syllabus}

\begin{tabular}{|c|c|c|c|c|c|c|c|c|c|}
\hline & & $\mathrm{EE} 301 \mathrm{Co}$ & e Schedul & $\mathrm{AY}$ & 18 & 2 & & & $\begin{array}{l}\text { Updateo: } \\
\text { ann2018 }\end{array}$ \\
\hline & \multirow{3}{*}{ DATE } & \multirow{3}{*}{ TOPIC } & \multirow{3}{*}{ READING } & \multirow{3}{*}{ LAB } & \multirow{3}{*}{ QUIZ } & \multicolumn{4}{|c|}{ ASSIGNMENT DUE } \\
\hline$s$ & & & & & & $\begin{array}{c}\text { C12, E23, } \\
\text { G28 }\end{array}$ & A1, G24 & D13, H25 & D21 \\
\hline \multirow{2}{*}{\multicolumn{10}{|c|}{ Basic Circuit Theory }} \\
\hline & & & & & & & & & \\
\hline 1 & $08 / 09$ ] IN & Introduction, Course Pollicies, Homor, Documentartion & None & & & & & & \\
\hline 2 & $10 / 11 \mathrm{aN}$ & Circuilt Elements, Current \& KCLL, Voltage \& KVL. & $1.5 \cdot 23$ & & & & & & \\
\hline 3 & $12 / 16 \mathrm{JaN}$ & Power, Resistance, Ohm's Law & $2.4 \cdot 2.6$ & Prep Lab- $\mathrm{R}$ & & & & & \\
\hline \multicolumn{10}{|c|}{ 500th NIGHT / MLK WEEKEND } \\
\hline 4 & $17 / 18$ jaN & Series/Parallel Clircults & $2.7 \cdot 2.9$ & Prep Lab-s & & & & & \\
\hline 5 & $19 / 22 \mathrm{JaN}$ & Voltage and Current Dividers & 2.7 .2 .9 & Prep Lab-T & & & & & \\
\hline \multicolumn{10}{|c|}{ DC Circuit Analysis } \\
\hline 6 & $23 / 24 / \mathrm{JN}$ & Therroduction to Nodal Analysis & $3.1 \cdot 3.2$ & & QUIZ & Prelab 1 & Prelab 1 & Prelab 1 & Prelab 1 \\
\hline 7 & $25 / 26 / \mathrm{aN}$ & Node Voltage Analysis w/ Voltage Sources & 32 & Prep Lab-U & & & & & \\
\hline 8 & $29 / 30 / 1 \mathrm{~N}$ & Thévenin and Norton Equlvalent Clrcults & $2.10,3.6$ & Lab 1-R & & & & & \\
\hline 9 & 31 / AN/01 FEB & Source Transformatton $s$ Marimum Power Transfer & $3.6 \cdot 3.7$ & Lab 1-s & QUIZ & HW 1 & HW1 1 & HW 1 & HW1 1 \\
\hline 10 & $02 / 05 \mathrm{FPB}$ & Revilew for WPR 1 & All previlous & Lab1-T & & Prelab 2 & Prelab 2 & Prelab 2 & Prelab 2 \\
\hline 11 & $06 / 07 \mathrm{FPB}$ & WPR 1 & & Lab1.U & & & & & \\
\hline \multicolumn{10}{|c|}{ Transient Analysis } \\
\hline 12 & $08 / 09 \mathrm{FPB}$ & Energy Storage Bements & 4.1 & Lab $2-R$ & & & & & \\
\hline 13 & $12 / 13 \mathrm{FPB}$ & $1^{*}$ Order Creults $\&$ Transient Analysis & $5.1 \cdot 5.2$ & Lab $2-\mathrm{S}$ & & Lab1 & & & \\
\hline 14 & $14 / 15$ Fes & Transient Analysis II & 53 & Lab2-T & & & Lab1 & & \\
\hline \multicolumn{10}{|c|}{ AC Circuit Analysis } \\
\hline \multirow{2}{*}{\multicolumn{10}{|c|}{ 100th NIGHT / PRESIDENTS DAY WEEKEND }} \\
\hline & & & & & & & & & \\
\hline 16 & $21 / 22 \mathrm{FPB}$ & Impediance and AC. Analysis & 45 & Project- $R$ & & & & & Lab 1 \\
\hline 17 & $23 / 26 \mathrm{FPB}$ & AC Node Voltage Analysis & 4.6 & Project -S & & $\begin{array}{l}\text { Lab 2/ } \\
\text { HW2 }\end{array}$ & HW 2 & HW 2 & HW 2 \\
\hline \multicolumn{10}{|c|}{ AC Power } \\
\hline 18 & 27 FEB/01 MAR & AC Power and Power Factor & 7.1 & Project - T & & Prelab 3 & $\begin{array}{l}\text { Prelab 3/ } \\
\text { Lab 2 }\end{array}$ & Prelab 3 & Prelab 3 \\
\hline 19 & $02 / 05$ MAR & Complex Power & $7.2 \cdot 73$ & Project $-U$ & & & & Lab2 & \\
\hline 20 & $06 / 07$ MAR & Transtormers//mpedance Transformation & 7.4 & Lab $3-R$ & & & & & Lab 2 \\
\hline 21 & $08 / 09$ MAR & Three Phase Power & 75 & & QUIZ & HW 3 & HW 3 & HW 3 & HW 3 \\
\hline \multicolumn{10}{|c|}{ Spring Break } \\
\hline 22 & $19 / 20 \mathrm{MAR}$ & Review for WPR 2 & All previous & Lab 3-5 & & & & & \\
\hline 23 & $21 / 22$ MAR & WPR 2 & & Lab3-T & & & & & \\
\hline \multicolumn{10}{|c|}{ Analog \& Digital Electronics } \\
\hline 24 & $23 / 26 \mathrm{MAR}$ & Operational Ampilifiers I & $8.1 \cdot 82$ & Lab $3-U$ & & & & & \\
\hline 25 & $27 / 28 \mathrm{MAR}$ & Operational Ampulifiers II & $8.4 \cdot 8.5,15.5$ & Project $-\mathrm{R}$ & & Lab 3 & & & \\
\hline 26 & $29 / 30$ MAR & Froquency Response and Passive Filters & $6.1,6.3$ & Project-S & & & Lab 3 & & \\
\hline & & & Easter & & & & & & \\
\hline 27 & $02 / 03$ APR & Active Filters & 8.3 & Project - T & QUIz & Prelab 4 & Prelab 4 & $\begin{array}{l}\text { Prelab 4/ } \\
\text { Lab 3 }\end{array}$ & Prelab 4 \\
\hline 28 & $05 / 06$ APR & Number Systems, Blinary Logic, and Boolean Algebra & $13.1 \cdot 13.3$ & Project - U & & & & & Lab 3 \\
\hline 29 & $09 / 10 \mathrm{APR}$ & $A / D$ and $D / A$ Conversions & 15.4 & Lab $4-R$ & & & & & \\
\hline 30 & $11 / 12 \mathrm{APR}$ & Revilew for WPR 3 & All previlous & Lab 4-5 & QUIZ & HW/4 & HW 4 & $\mathrm{HW} 4$ & $\mathrm{HW} 4$ \\
\hline 31 & $13 / 16$ APR & WPR 3 & & Lab4-T & & & & & \\
\hline & & & Sandhurst & & & & & & \\
\hline & & & T/ Communications & & & & & & \\
\hline 32 & $17 / 18$ APR & Networking 1 & 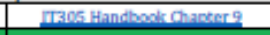 & L.ab 4-U & & & & & \\
\hline 33 & $19 / 20$ APR & Class Drop - Mission Command Conferenos & & ITLab-R & & & & & \\
\hline 34 & $23 / 24 \mathrm{APR}$ & Networking 2 & IT305 Handhook Chanter I0 & ITlab-S & & Lab 4 & & & \\
\hline 35 & $25 / 26$ APR & Networking 3 & 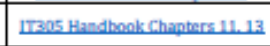 & Tr Lab-T & & Project & $\begin{array}{c}\text { Prolect/ } \\
\text { Lab4 }\end{array}$ & Project & Project \\
\hline 36 & $27 / 30 \mathrm{APR}$ & Radio Principles & \begin{tabular}{|l|}
16.3 \\
\end{tabular} & I L Lab-U & & & & Lab4 4 & \\
\hline 37 & $01 / 02 \mathrm{MAY}$ & Radilo Recelvers & 16.3 & & & & & & Lab 4 \\
\hline & & & PROJECTS DAY & & & & & & \\
\hline 38 & $04 / 07 \mathrm{MAY}$ & Milltary Power Applikations & $7.6 \cdot 7.7$ & & QUIZ & & & & \\
\hline 39 & $08 / 09 \mathrm{MAY}$ & Residential Wirling and Power Ceneration/Distribution & $7.6 \cdot 7.7$ & & & & & & \\
\hline 40 & $10 / 11 \mathrm{MAY}$ & TE Revilew & All prevlous & & & & & & \\
\hline
\end{tabular}

